\title{
PERCUTANEOUS SCREW REMOVAL IN SLIPPED UPPER FEMORAL EPIPHYSIS
}

\author{
MARTIN A. GRUBER， KEITH D. STARKWEATHER， WILLIAM \\ A. HEALY III, SUSAN HARALABATOS \\ From the State University of New York, Stony Brook, USA
}

\begin{abstract}
Geveral authors have reported complications from Sscrew removal after treatment of slipped upper femoral epiphysis by single screw fixation, and have attributed these to poor screw design. We have developed a simple and reliable method of screw removal which uses a cannulated $8.0 \mathrm{~mm}$ end-threaded cancellous screw (Smith \& Nephew Richards Medical, Memphis, Tennessee) and a specially designed cannulated trephine.

The method has been successful, with minimal complications, and a limited surgical exposure.
\end{abstract}

J Bone Joint Surg [Br] 1996;78-B:137-9.

Received 25 April 1995; Accepted after revision 28 June 1995

Slipped upper femoral epiphysis (SUFE) is the most common hip disorder in adolescents (Tachdjian 1990). Left untreated or neglected, slip tends to increase, which exacerbates the deformity and adversely affects the long-term outcome (Hall 1957). The goal of surgical treatment is to prevent further slipping and to induce physeal closure (Lehman et al 1984; Stambough et al 1986; Lehman 1988). Treatment has evolved into standard fixation by a single screw (Stambough et al 1986; Crawford 1988; Ward et al 1992).

Several authors have reported complications, however, should the screw need to be removed after physeal closure (Swiontkowski 1983; Greenough, Bromage and Jackson 1985; Larsson and Friberg 1987; Crandall, Gabriel and Akbarnia 1992; Warner, Bramley and Kay 1994). One of us (MAG) therefore developed a new and reliable method of

M. A. Gruber, MD, FAAOS, FAAP, Professor of Clinical Orthopaedics and Paediatrics

K. D. Starkweather, MD, Resident in Orthopaedic Surgery

W. A. Healy III, MD, Resident in Orthopaedic Surgery

S. Haralabatos, MD, Paediatric Orthopaedic Fellow

Division of Paediatric Orthopaedics, Department of Orthopaedics, Stony

Brook Health Sciences Centre, State University of New York at Stony Brook, Stony Brook, New York 11794-8181, USA.

Correspondence should be sent to Professor M. A. Gruber.

(C)1996 British Editorial Society of Bone and Joint Surgery 0301-620X/96/11114\$2.00 removal, with few complications. We report our preliminary experience with this technique which is easy to learn and minimally invasive.

\section{PATIENTS AND METHODS}

We used a cannulated $8.0 \mathrm{~mm}$ end-threaded cancellous screw (Smith \& Nephew Richards Medical, Memphis, Tennessee) which is readily available. It has a prominent head which is the male portion of a hexagonal socket (Fig. 1). This increases the contact area between the screwdriver and screw head, and reduces the risk of stripping the screw head during removal. The contact area in this screw head is $82.0 \mathrm{~mm}^{2}$ compared with approximately $40 \mathrm{~mm}^{2}$ in female hexagonal screw heads. The screwdriver is the female portion of the socket. This arrangement tends to clean soft tissue from the screw head as the screwdriver is locked into place. The triflanged screw tip is self-tapping and has reverse cutting flutes for easier removal. The thick core of the screw helps to protect against shear failure.

Screw removal is performed with the patient on a fracture table, using biplane fluoroscopy to pass a guide pin percutaneously into the cannula of the screw. If the screw head is overgrown by bone, a drill is used to advance the sharp end-threaded guide pin through the bone into the screw cannula. Once the guide is in place, a $1.5 \mathrm{~cm}$ longitudinal incision is centred on the pin and a cannulated soft-tissue dilator is inserted over the pin to expand the skin and subcutaneous tissues.

A cannulated reamer is then passed through the softtissue protector and used to ream away any bone and fibrous tissue that may have overgrown the screw head. The reamer is removed, and a cannulated trephine is advanced by hand along the guide pin until it sits on the screw head (Figs 2 to 4). This cleans bone and fibrous tissue away from the hexagonal head, and this is complete when the trephine reaches a flared stop at the base of the screw head.

The trephine is then removed and the screwdriver is advanced along the guide pin until it sits completely on the screw head, as confirmed by fluoroscopy. The guide pin is removed, and a locking pin is inserted through the screwdriver to lock the screw and screwdriver together. The screw is then removed.

The incision is closed with a subcutaneous absorbable suture and sterile adhesive strips. An elastic bandage spica dressing is retained for 24 hours, but patients are allowed to 


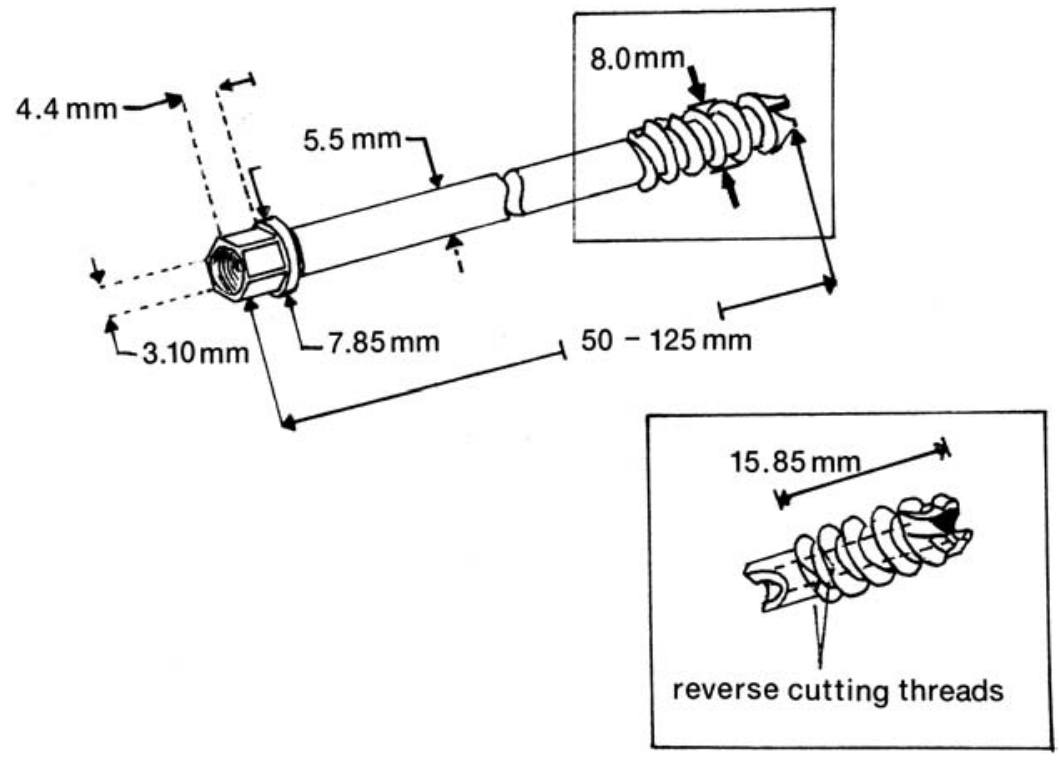

Fig. 1

Diagram showing the male hexagonal head, the dimensions, and the characteristics of the tip of the $8.0 \mathrm{~mm}$ cannulated screw.

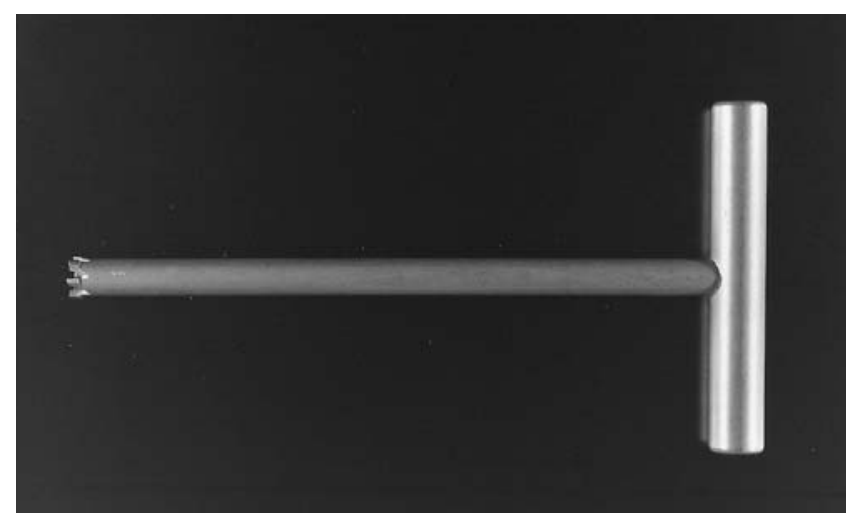

Fig. 2

The cannulated trephine.

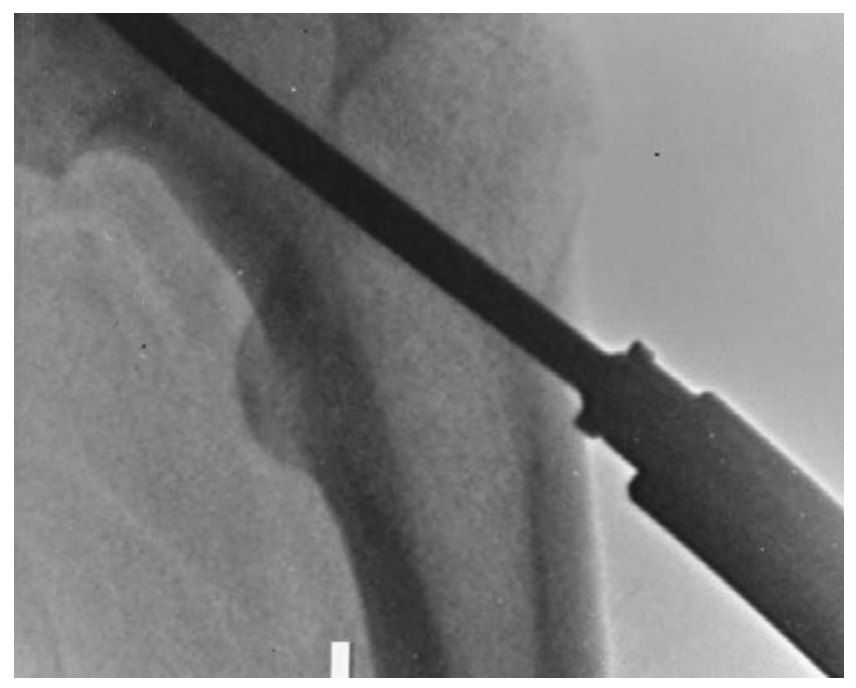

Fig. 3

Radiograph showing the cannulated trephine in the soft-tissue protector, fully seated on the screw head.

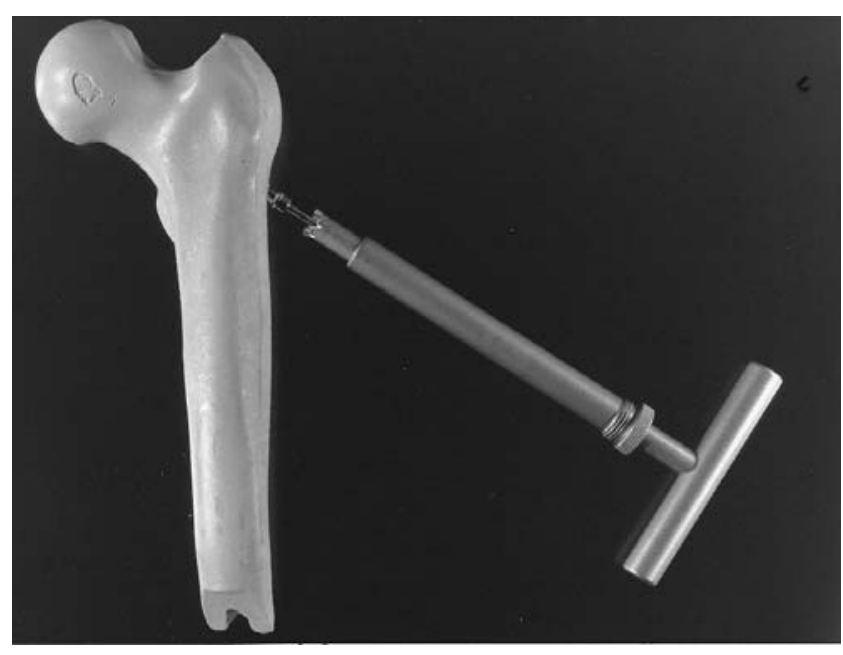

Fig. 4

The T-handled cannulated trephine within the soft-tissue protector, placed over the guide pin before engaging the screw head.

bear full weight and leave hospital on the same day. Full activities are permitted after six weeks.

\section{RESULTS}

We reviewed the records of all patients with SUFE who had had percutaneous removal of $8.0 \mathrm{~mm}$ cannulated screws between June 1993 and January 1995, excluding those who had had other procedures at the same time. Ten patients (16 hips) met the criteria; nine were male and six had bilateral screws. The mean age at the time of fixation had been 13 years 1 month (11 years 11 months to 14 years 10 months); the screws were removed at a mean of 17.1 months after insertion (9 to 34).

Four unilateral screw removals took a mean operating time of 30.5 minutes (15 to 50) and six bilateral procedures 
occupied a mean operating time of 60 minutes (35 to 95). All patients were discharged within 24 hours.

There were no cases of infection, haematoma, fracture, metal failure, or neurovascular complications.

\section{DISCUSSION}

The treatment of SUFE by single screw fixation is common but the type of screw and the ability to remove it safely and reliably are still under discussion. Several authors have reported complications including bent and broken screws, fractures, secondary osteomyelitis, inability to remove screws, prolonged operating time, and delayed recovery (Greenough et al 1985; Larsson and Friberg 1987; Crandall et al 1992; Warner et al 1994). These problems have led some authors to advise against screw removal unless it is absolutely necessary.

We have shown that the use of an $8.0 \mathrm{~mm}$ cannulated screw with a male hexagonal screw head facilitates removal, using a cannulated trephine through a limited surgical approach. This technique has allowed consistently uncomplicated screw removal, with minimal operating time, surgical exposure, and hospital stay.

No benefits in any form have been received or will be received from a commercial party related directly or indirectly to the subject of this article.

\section{REFERENCES}

Crandall DG, Gabriel KR, Akbarnia BA. Second operation for slipped capital femoral epiphysis: pin removal. J Pediatr Orthop 1992;12: 434-7.

Crawford AH. Slipped capital femoral epiphysis. J Bone Joint Surg [Am] 1988;70-A:1422-7.

Greenough CG, Bromage JD, Jackson AM. Pinning of the slipped upper femoral epiphysis: a trouble-free procedure? J Pediatr Orthop 1985;5: 657-60.

Hall JE. The results of slipped capital femoral epiphysis. J Bone Joint Surg 1957;39-B:659-73.

Larsson S, Friberg S. Complications at extraction of the ASIF epiphysiodesis screws. Acta Orthop Scand 1987;58:483-4.

Lehman WB. Slipped capital femoral epiphysis. In: Dee R, ed. Principles of orthopaedic practice. New York: McGraw Hill, 1988:1101-9.

Lehman WB, Menche D, Grant A, Norman A, Pugh J. The problem of evaluating in situ pinning of slipped capital femoral epiphysis: an experimental model and a review of 63 consecutive cases. J Pediatr Orthop 1984;4:297-303.

Stambough JL, Davidson RS, Ellis RD, Gregg JR. Slipped capital femoral epiphysis: an analysis of 80 patients as to pin placement and number. J Pediatr Orthop 1986;6:265-73.

Swiontkowski MF. Slipped capital femoral epiphysis: complications related to internal fixation. Orthopedics 1983;6:705-12.

Tachdjian MO. Slipped capital femoral epiphysis. In: Wickland EH Jr, ed. Pediatric orthopaedics. 2nd edition. Philadelphia: WB Saunders Co., 1990:1016-81.

Ward WT, Stefko J, Wood KB, Satnitski CL. Fixation with a single screw for slipped capital femoral epiphysis. J Bone Joint Surg [Am] 1992;74-A:799-809.

Warner JG, Bramley D, Kay PR. Failure of screw removal after fixation of slipped capital femoral epiphysis: the need for a specific screw design. J Bone Joint Surg [Br] 1994;76-B:845-6. 